Hideyuki Suzuki - M. S. Srinivasa Reddy

Marina Naoumkina · Naveed Aziz · Gregory D. May

David V. Huhman · Lloyd W. Sumner - Jack W. Blount

Pedro Mendes · Richard A. Dixon

\title{
Methyl jasmonate and yeast elicitor induce differential transcriptional and metabolic re-programming in cell suspension cultures of the model legume Medicago truncatula
}

\author{
Received: 24 June 2004 Accepted: 11 August 2004 Published online: 17 December 2004 \\ (c) Springer-Verlag 2004
}

\begin{abstract}
Exposure of cell suspension cultures of Medicago truncatula Gaerth. to methyl jasmonate (MeJA) resulted in up to 50 -fold induction of transcripts encoding the key triterpene biosynthetic enzyme $\beta$-amyrin synthase ( $\beta$ AS; EC 5.4.99.-). Transcripts reached maximum levels at $24 \mathrm{~h}$ post-clicitation with $0.5 \mathrm{mM}$ MeJA. The entry point enzymes into the phenylpropanoid and flavonoid pathways, L-phenylalanine ammonia-lyase (PAL; EC 4.3.1.5) and chalcone synthase (CHS; EC 2.3.1.74), respectively, were not induced by MeJA. In contrast, exposure of cells to yeast elicitor (YE) resulted in up to 45- and 14-fold induction of PAL and CHS transcripts, respectively, at only $2 \mathrm{~h}$ postelicitation. $\beta$ AS transcripts were weakly induced at $12 \mathrm{~h}$ after exposure to YE. Over 30 different triterpene saponins were identified in the cultures, many of which were strongly induced by MeJA, but not by YE. In contrast, cinnamic acids, benzoic acids and isoflavonederived compounds accumulated following exposure of cultures to YE, but few changes in phenylpropanoid levels were observed in response to MeJA. DNA microarray analysis confirmed the strong differential transcriptional re-programming of the cell cultures for
\end{abstract}

Electronic Supplementary Material Supplementary material is available in the online version of this article at http://dx.doi.org 10.1007/s00425-004-1387-2

H. Suzuki · M. S. S. Reddy · M. Naoumkina $\cdot$ N. Aziz

G. D. May D. V. Huhman

L. W. Sumner $\cdot$ J. W. Blount $\cdot$ R. A. Dixon $(区)$

Plant Biology Division, Samuel Roberts Noble Foundation,

2510 Sam Noble Parkway, Ardmore, OK 73401, USA

E-mail: radixon (a noble org

Tel.: + 1-580-2246601

Fax: $+1-580-2246692$

P. Mendes

Virginia Bioinformatics Institute, Virginia Polytechnic Institute and State University. Blacksburg, VA 24060, USA

Present address: H. Suzuki

Kazusa DNA Research Institute. 2-6-7-Kazusa-Katamari.

Kisarazu-shi, 292-(0818 Chiba. Japan multiple genes in the phenylpropanoid and triterpene pathways in response to MeJA and YE, and indicated different responses of individual members of gene families. This work establishes Medicago cell cultures as an excellent model for future genomics approaches to understand the regulation of legume secondary metabolism.

Keywords $\beta$-Amyrin synthase $\cdot$ Chalcone synthase Elicitation $\cdot$ Medicago $\cdot$ L-Phenylalanine ammonialyase $\cdot$ Triterpene saponins

Abbreviations ABA: Abscisic acid - $\beta$ AS: $\beta$-Amyrin synthase $\cdot$ CHS: Chalcone synthase $\cdot$ EST: Expressed sequence tag - MeJA: Methyl jasmonate PAL: L-Phenylalanine ammonia-lyase $\cdot$ SA: Salicylic acid - TC: Tentative consensus ' YE: Yeast elicitor

\section{Introduction}

The model legume Medicago truncatula (barrel medic) is rapidly developing into a model system for plant functional genomics (Cook 1999; Oldroyd and Geurts 2001; May and Dixon 2004). Resources include nearly 200,000 publicly available EST sequences (http://www.tigr.org/ $\mathrm{tdb} / \mathrm{mtgi} /$ ), a genome sequencing project (http:// www.genome.ou.edu) to be completed in 2007, availability of a $16-\mathrm{K}$ unigene oligonucleotide set for DNA microarrays (http://oligos.qiagen.com/arrays/oligosets_medicago.php), development of transposon- and fast neutron-mutagenized populations (d'Erfurth et al. 2003), and high-throughput metabolome and proteome analytical capabilities (Mathesius et al. 2001; BestelCorre et al. 2002; Sumner et al. 2003; Watson et al. 2003).

Legumes such as $M$. truncatula are rich sources of bioactive natural products (Dixon and Sumner 2003). Particularly important are the triterpene saponins, 
which. collectively, protect the plant by nature of their anti-microbial (Osbourn 2003). anti-insect (Tava and Odoardi 1996) and anti-palatability and anti-nutritional (Small 1996: Oleszek et al. 1999) activities. Saponins also exhibit anticholesterolemic, anti-cancer (Haridas et al. 2001). adjuvant (Behboudi et al. 1999), and hemolytic $(\mathrm{Oh}$ et al. 2000) activity, and are important components of a number of herbal medicines (Lee et al. 200)(0) Xu 2001). Whole plants of 11. Huncutula contain over 30) different triterpene saponins. present as a series of mono-. di- and triglycosides of tive major triterpene aglycones (Huhman and Sumner 20(02). In spite of the potential importance of these compounds for human health and agriculture. little is known of the genes involved in their biosynthesis in legumes.

A second important group of legume natural products. the isoflatonoids, is better understood at the molecular genetic level (Dixon et al. 1995: Dixon 1999: Shimada et al. 2000): Steele et al. 1999). Nevertheless, some areas of isoflavonoid metabolism, such as dehydration and glycosylation reactions, and the specific reactions of coumestan biosynthesis, have yet to be clucidated at the molecular level (Dixon 1999). Furthermore. little is known concerning the transcription factors that co-ordinate the expression of the various branches of the triterpene and isoflavonoid pathways in legumes.

In a previous publication. we described methyl jasmonate (MeJA) induction of early triterpene pathway genes in 1\%. Hunc atula cell suspension cultures (Suzuki et al. 20(2) 2). We now extend these studies by optimizing the 1/edicteos cell culture system for induction of triterpene and phenylpropanoid metabolism in response to different elicitors providing a detailed analysis of the triterpene compounds induced in response to MeJA. and carrying out a preliminary metabolite profiling and transcript expression analysis (using DNA microarrays) to Validate the use of the Medicago cell culture system for gene discovery in natural product biosynthesis. We discuss variation in the response of different batehes (passiges) of plant cell cultures in relation to the use of such material for integrated functional genomics studies.

\section{Materials and methods}

\section{Plant material}

Cell suspension cultures were initiated via callus from roots of Medicago truncutula Gaerth 'Jemalong' (line A 17) plants, maintained in a modified Schenk and Hildebrandt medium (Dixon et al. 1981), and subcultured every 10 14 day's. Elicitation experiments were performed with two different suspension cultures, derived from the original root callus material at different times. Culture I wats elicited on the 8 th day of the 7th passage in liquid culture. and culture II on the 8th day of the 1th passiage.
Five or 8 days after subculture, dark-grown suspension cultures (40-ml batches) were treated with MeJA (0.5-5.000 $\mu \mathrm{M}$ final concentration, delivered in $0.8 \mathrm{ml}$ of ethanol), yeast elicitor (YE; Schumacher et al. 1987; 0.4 $200 \mu \mathrm{g}$ glucose equivalents/ml), salicylic acid (SA: $500 \mu \mathrm{M})$ or abscisic acid (ABA; $500 \mu \mathrm{M})$, harvested at various times after elicitation and frozen at $-80^{\circ} \mathrm{C}$. MeJA and ABA control cells were treated with $0.8 \mathrm{ml}$ of ethanol, and controls for YE and SA clicitations with $0.8 \mathrm{ml}$ distilled water.

\section{RNA gel blot analysis}

Total RNA was isolated from $0.5 \mathrm{~g}$ of $M$. truncitula suspension cells using $5 \mathrm{ml}$ of Tri-Reagent (Molecular Research Center, Cincinnati. OH, USA) following the manufacturer's protocol. Thirty micrograms of RNA was separated by electrophoresis in a $1.2 \%$ agarose gel containing $0.66 \mathrm{M}$ formaldehyde and then blotted onto a Hybond- $\mathrm{N}^{+}$membrane (Amersham Biosciences. Piscataway, NJ, USA). The entire cDNA fragments of the $M$. truncatula $\beta$ AS (Noble Foundation clone \# NF(051E06IN), L-phenylalanine ammonia-lyase (PAL; NF(11C12ST), and chalcone synthase (CHS: NF044D07EC) expressed sequence tag (EST) clones and 18S-rRNA were radiolabeled with [ ${ }^{3}$ P]dCTP using a Ready-to-Go DNA Labeling Beads (-dCTP) kit (Amersham), and used as probes. RNA blot hybridization and washing were done essentially as described in Sambrook et al (1989).

Extraction and HPLC analysis of phenolic compounds

One-gram batches of frozen cells were extracted and analyzed for soluble phenolics by HPLC as previously described (Howles et al. 1996). Compounds were monitored with a diode array detector at 310,287, 270 and $254 \mathrm{~nm}$. The wall-bound phenolics were released from the cell residues that had been extracted for soluble phenolics as previously described (Blount et al. 2002) and analyzed by HPLC as above. Samples were applied to an ODS2 reverse-phase column (J.T. Baker, Phillipsburg, NJ. USA; $5 \mu \mathrm{m}$ particle size, $4.6 \times 250 \mathrm{~mm}$ ) and cluted in $1 \%(\mathrm{v} / \mathrm{v})$ phosphoric acid with an increasing concentration gradient of acetonitrile $[0-5 \mathrm{~min}, 5 \%(\mathrm{v}$ v) : $5-10 \mathrm{~min}, 5-10 \% ; 10-25 \mathrm{~min}, 10-17 \% ; 25-30 \mathrm{~min}$. $17-23 \%$; 30-65 min, $23-50 \%$ ] at a flow rate of $1 \mathrm{ml} \min$.

For analysis of phenolic compounds in the culture medium. medium was separated from cell cultures and was extracted three times with ethyl acetate prior to analysis of the organic fraction as above.

For extraction of triterpenes, $1 \mathrm{~g}$ fresh weight of cell culture was powdered using liquid nitrogen and extracted in $10 \mathrm{ml}$ of $80 \%$ methanol overnight at room temperature. The samples were centrifuged at $1.000 \mathrm{~g}$ for $45 \mathrm{~min}$, and $8.5 \mathrm{ml}$ of supernatant was removed and 
concentrated to its aqueous component. The sample was then loaded onto a pre-equilibrated C-18 SPE cartridge $(3 \mathrm{ml}, 100 \mathrm{mg}$; International Sorbent Technology. Hengoed, Mid Glamorgan, UK), which was washed with one column volume each of $100 \%$ water and $35 \%$ aqueous methanol. Saponins were eluted with $1.3 \mathrm{ml}$ of $100 \%$ methanol. The methanol fraction was taken to dryness under a nitrogen stream, and re-suspended in $250 \mu \mathrm{l}$ methanol. HPLC separation was achieved using a reverse-phase, C18, 5- $\mu \mathrm{m}, 4.6 \times 250-\mathrm{mm}$ column (J.T. Baker). Samples $(30 \mu \mathrm{l})$ were eluted with a linear gradient of $0.1 \%$ aqueous acetic acid: $\mathrm{CH}_{3} \mathrm{CN}, 95: 5$ to $30: 70$ in $65 \mathrm{~min}$, at a flow rate of $0.8 \mathrm{ml} \mathrm{min}$.

All mass spectra were acquired using a Bruker Esquire LC equipped with an electrospray ionization (ESI) source operated in the negative ion mode using a source voltage of $3,000 \mathrm{~V}$ and capillary offset voltage of $-70.7 \mathrm{~V}$. Nebulization was achicved using concurrent nitrogen gas at a pressure of $70 \mathrm{psi}$. Desolvation was aided by using a counter-current of nitrogen at a pressure of 12 psi. The capillary temperature was set at $360^{\circ} \mathrm{C}$. Mass spectra were recorded over the range of 50 $2,200 \mathrm{~m} / \mathrm{z}$. The Bruker ion-trap was operated under an ion current control of 20,000 and a max acquire time of $100 \mathrm{~ms}$ with a trap drive setting of 60 .

\section{DNA microarray analysis}

Details of the DNA oligonucleotide arrays are given in the Electronic Supplementary Material. Total RNA was isolated using Tri-Reagent. mRNA was isolated from $200 \mu \mathrm{g}$ of total RNA using a Poly(A)Purist MAG Kit (Ambion, Austin, TX, USA). The Amino Allyl cDNA Labeling Kit (Ambion) was used to label $3 \mu \mathrm{g}$ of $\mathrm{mRNA}$ following the manufacturer's protocol. The product was resuspended in $50 \mu \mathrm{l}$ of Microarray Hybridization Solution, Version 2 (Amersham Biosciences), denatured at $95-100^{\circ} \mathrm{C}$ for $2 \mathrm{~min}$, then pipetted onto the slides and coverslip (Corning, Corning, NY, USA) before sealing into a hybridization chamber (Corning). The sealed chamber was wrapped in aluminum foil and incubated at $42^{\circ} \mathrm{C}$ for $16-24 \mathrm{~h}$. The arrays were subsequently washed with $1 \times$ SSC, $0.1 \%(\mathrm{w} / \mathrm{v}) \mathrm{SDS}$, followed by a wash in $0.5 \times \mathrm{SSC}, 0.01 \% \mathrm{SDS}$, and a third wash with $0.05 \times$ $\mathrm{SSC}$, at room temperature for $5 \mathrm{~min}$ each. The slides were dried by centrifugation.

Arrays were read with a ScanArray 4000 scanner (Packard, Palo Alto, CA, USA) at $10 \mu \mathrm{m}$ resolution and variable photomultiplier tube voltage settings to obtain the maximal signal intensities with $<1 \%$ probe saturation. The fluorescence intensity for each fluor and each element on the array was captured using GencPix Pro 4.1 (Axon, Union City, CA, USA). The local background was subtracted from the values of each spot on the array. Cy 3 and $\mathrm{Cy} 5$ signals were normalized by adjusting the signal intensities of the two images (Global Normalization). The average of normalized signal intensities of all four elements for each gene (three rep- licate hybridizations and one dye-swap) was calculated and used for further analysis. Significance of results was determined using SAM scatter-plot analysis (Goss et al. 2001). Cluster analysis (hierarchical clustering. distance metric Pearson correlation. average clustering method) was performed using Genetraffic (Iobion Informatics LLC. La Jolla, CA. USA) software.

Reverse transcription polymerase chain reaction (RT PCR) analysis

DNA array results were confirmed by $R T$ P('R using tentative consensus (TC)-specific primers. Four $\mu$ g of total RNA was used in a first-strand synthesis using Ready-To-Go RT PCR Beads (Amersham Biosciences) in a $50-\mu l$ reaction with oligo-dT primers according 10 the manufacturer's protocol. Four $\mu$ of the first-strand reaction was then PCR-amplified for 30 cycles using Takara Ex Taq (Fisher Scientific, Palatine. IL. USA) according to the manufacturer's protocol. The PCR products were then analyzed on an agarose gel.

The sequences of the TC-specific primers used for the $P C R$ reactions were:

PAL (TC51375), forward 5'-ACAGGGAGTCATTTGGATGAGGTG-3'. reverse 5'-GGAACTC 'CTAATCAACATGTTGACG-3':

CCOAOMT (TC52452). forward 5'-T(jTTTACC(TAGAGAGCCTGAGCC-3'. rererse 5'-GTG(jTC'TAGAATGCATTGGAACTTTC $-3^{\prime}$ :

CCOAOMT (TC51699) forwall 5'-GTGTGTTTCCAAATGAACACCCTTG-3'. reverse $5^{\prime}$-C $C^{\prime} A C G$ TAAACGTTTAACGAAATCCAG-3':

squalene epoxidase (SE: TC51619) forward 5'-C(GCGGATCCATGGATCTATACAATATCGGTTGG-3'. reverse 5'-CTAGCTAGCTCAAAATGCATTTACCGGGGGAGC-3':

BAS (TC52533) forward 5'-ACGCGTCOACATGCAAACAATAGATGGAGTGAAG-3'. reverse 5'-CCGCTCGAGAACTGCAGTGGAAG(jCAATGGAAC $-3^{\prime}$ :

actin (TC43462) forward 5'-GGCTGGATTTGCTGGAGATGATGC-3'. reverse 5'-CAATTTCTC (iCTCTGCTGAGGTGG-3'.

\section{Results and discussion}

Quantitative and temporal responses of cell cultures to $\mathrm{YE}$ and MeJA

To optimize the cell culture system for analysis of natural product pathway gene expression. IDNA probes for the three entry-point enzymes into the triterpene. phenylpropanoid and flavonoid branch pathways. BAS. PAL and CHS, respectively, were designed and used in RNA gel blot analyses to monitor corresponding transcript levels in cell cultures (culture I. see Materials and 
methods) exposed to various concentrations of MeJA over different time periods.

Increasing concentrations of MeJA from 5 to $500 \mu \mathrm{M}$ resulted in an accumulation of $\beta A S$ transcripts, with maximum levels (over 50 -fold increase from the zero value) recorded $24 \mathrm{~h}$ after exposure to $500 \mu \mathrm{M}$ MeJA (Fig. la,d). The time of attainment of maximum transcript accumulation increased with higher MeJA concentrations (Fig. Id). The highest MeJA concentration tested. $5 \mathrm{mM}$, was presumably toxic to the cells, as no $\beta A S$ transcripts were recorded. In contrast, PAL and CHS transcripts were only induced weakly, by approximately 3-fold, at $2 \mathrm{~h}$ after exposure to $5 \mu \mathrm{M}$ MeJA (Fig. 1a-c); higher concentrations did not induce the phenylpropanoid/flavonoid pathway genes. Control cells treated with ethanol (used for dilution of MeJA) showed decreasing levels of PAL and CHS transcripts and no appearance of $\beta$ AS transcripts over the 48-h time-course (data not shown). In a separate experiment, the response to $500 \mu \mathrm{M} \mathrm{MeJA}$ was recorded up to 7 days post-elicitation (see Electronic Supplementary Material). There was no additional response in the cultures beyond the $48 \mathrm{~h}$ initially examined, and $\beta \mathrm{AS}$ transcript levels gradually declined from their maximum.

Fig. la-d Induction of triterpene and phenylpropanoid pathway gene transcripts in Medicago truncatula cell suspension cultures (culture I) exposed to MeJA. Total RNA was isolated from elicited and control cell cultures at the various times shown, resolved by agatrose gel electrophoresis, blotted and hybridized with $M$. trunc'atula $\beta$-amyrin synthase ( $\beta$ AS), phenylalanine ammonia-lyase $(P A L)$ and chalcone synthase (CHS) cDNAs. 18S rRNA was probed as a control for equal loading and transfer of RNA. a Blots for cells exposed to $500 \mu \mathrm{M}$ MeJA. Blots were quantified by phosphorimager analysis, and data plotted with normalization to the zero-time value as $100 \%$. b-d Complete dose response to MeJA for PAL (b). CHS (c) and $\beta \mathrm{AS}$ (d). $0.5 \mu \mathrm{M}, 5 \mu \mathrm{M}, \boldsymbol{\Delta} 50 \mu \mathrm{M}$, - $500 \mu \mathrm{M} . \bigcirc 0.5 \mathrm{mM}$
There was no response in the ethanol-treated control cultures.

The above experiments were repeated using the same cell culture batch with YE in place of MeJA (Fig. 2). Increasing the concentration of YE from 0.4 to $200 \mu \mathrm{g}$ glucose equivalents $\mathrm{ml}^{-1}$ resulted in an increasing induction of PAL and CHS transcripts, with maximum levels (over 30-fold increase in the case of PAL) recorded at only $1-2 \mathrm{~h}$ post-elicitation (Fig. $2 \mathrm{a}-\mathrm{c}$ ). The induction kinetics of PAL and CHS were similar at all YE concentrations, except for a slower decline in CHS transcript levels at the optimum YE concentration (Fig. 2c). In contrast, $\beta \mathrm{AS}$ transcripts were only induced approximately 3.5 -fold, at around $12 \mathrm{~h}$ post-elicitation, with YE concentrations above $4 \mu \mathrm{g}$ glucose equivalents $\mathrm{ml}^{-1}$ (Fig. 2d). In a 7-day induction experiment, there was no further accumulation of PAL or CHS transcripts after the initial early response to $\mathrm{YE}$ or in water-treated controls (data not shown).

It has been suggested that MeJA is a common signal component in the induction pathway of many defenseresponsive plant natural products (Mueller et al. 1993), and the clear qualitative and temporal differences in the response of the $M$. truncatula cells to MeJA and YE was therefore not necessarily expected. If MeJA were an obligatory signal in YE-mediated responses, exposure to MeJA would be expected to result in a similar response to that of YE, but perhaps with faster kinetics, whereas the responses to the two elicitors were qualitatively different, and the response to MeJA was significantly slower than that to YE. The present kinetic results, coupled with the very different transcriptional re-programming of the cultures in response to MeJA and $\mathrm{YE}$, indicate that MeJA is unlikely to be involved in YE signaling for PAL and CHS induction in M. truncatula.

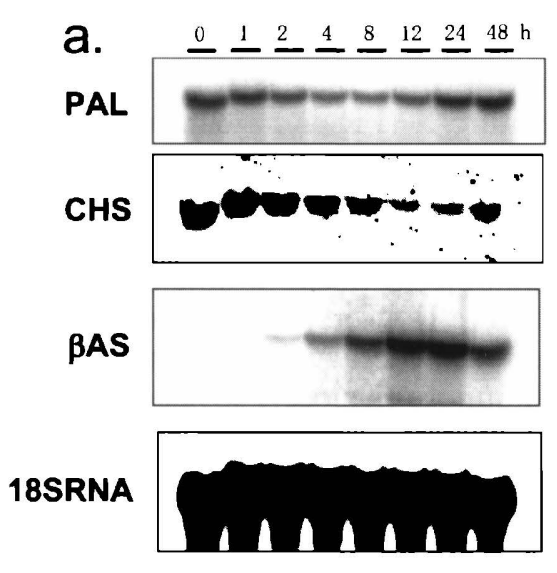

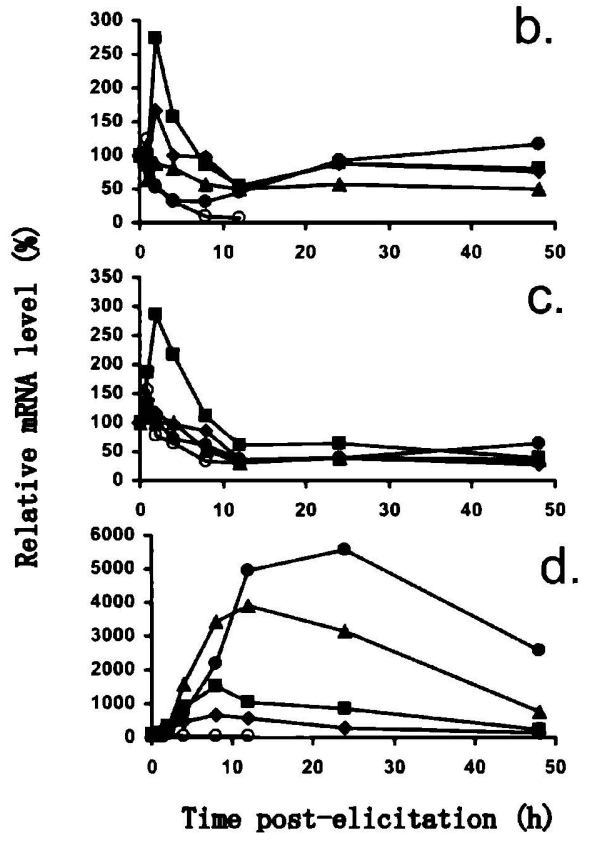


Fig. 2a-d Induction of triterpene and phenylpropanoid pathway gene transcripts in $M$. truncatula cell suspension cultures exposed to $\mathrm{YE}$ (culture I). Details are as in the legend to Fig. 1. a Blots for cells exposed to $200 \mu \mathrm{g}$ glucose equivalents $\mathrm{ml}^{-1} \mathrm{YE}$. Blots were quantified by phosphorimager analysis, and data plotted with normalization to the zero-time value as $100 \%$. b-d Complete dose response to YE for PAL (b), CHS (c) and $\beta A S(d) . ~ 0.4 \mu \mathrm{g}$ glucose equivalents $\mathrm{ml}^{-1}, \boldsymbol{\Delta} 4 \mu \mathrm{g}$ glucose equivalents $\mathrm{ml}^{-}$, $40 \mu \mathrm{g}$ glucose equivalents $/ \mathrm{ml}$, - $200 \mu \mathrm{g}$ glucose equivalents $\mathrm{ml}^{-1}$
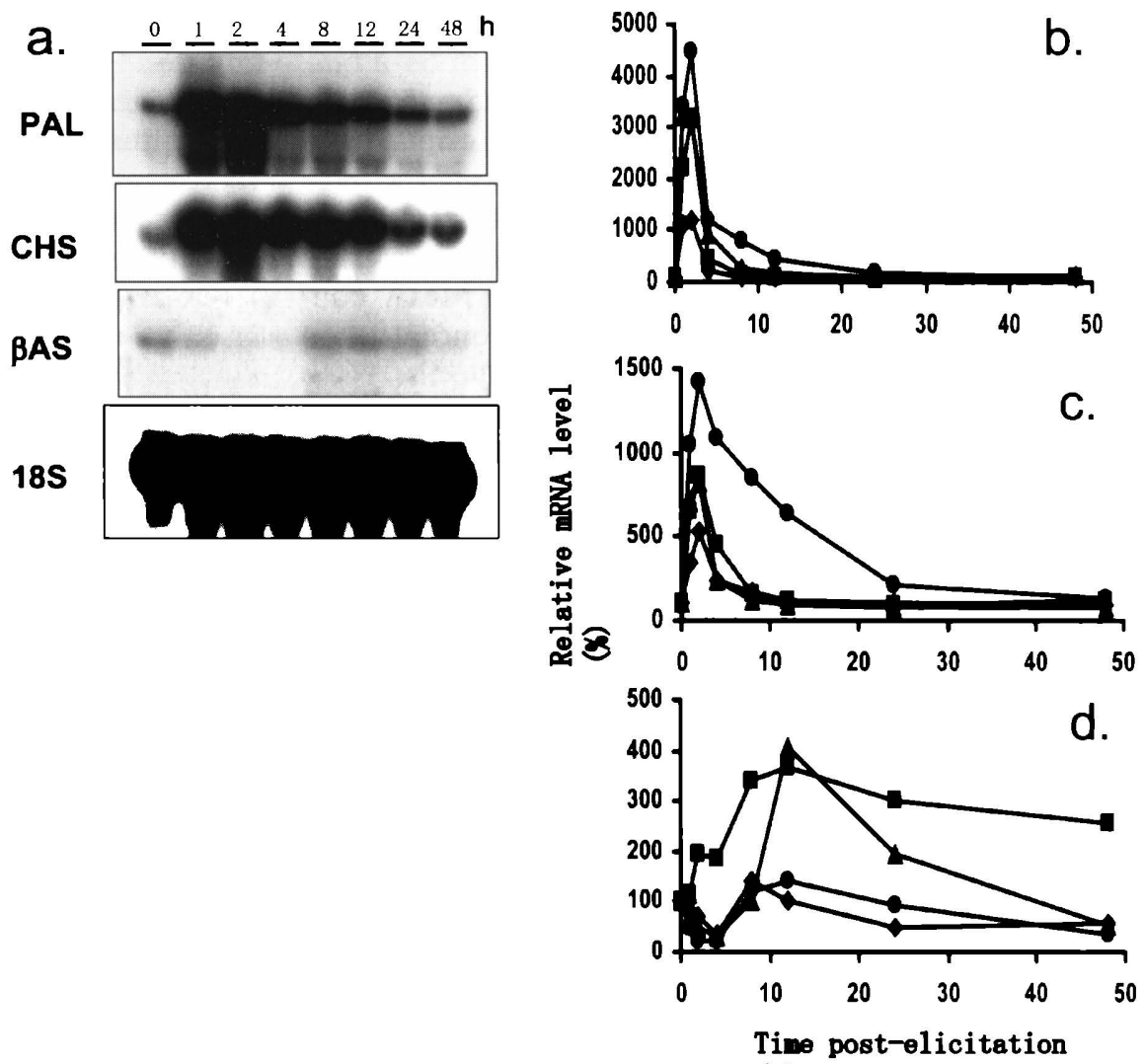

(h)
Responses to abscisic acid and salicylic acid

Abscisic acid (ABA) and salicylic acid (SA) are well known signal transducers for wound and microbial defense responses in plants (Hildmann et al. 1992; Klessig and Malamy 1994), and have been used as elicitors or potentiators of secondary metabolic pathways in cell culture systems (Dixon and Fuller 1978; Shirasu et al. 1997). Treatment of $M$. truncatula cell cultures with $500 \mu \mathrm{M}$ ABA resulted in only a very weak induction of PAL and CHS transcripts (data not shown), with no induction at lower concentrations. In contrast, exposure to SA resulted in an approximately 6-fold induction of both PAL and CHS transcripts at $2 \mathrm{~h}$ post-elicitation, but little effect on $\beta$ AS transcripts (see Electronic Supplementary Material). Because of the weakness of the effects of SA and ABA compared with those of YE and MeJA, these alternative elicitors were not investigated further.

Changes in triterpenoids in response to MeJA and YE

To determine the nature and extent of induced triterpene biosynthesis in Medicago cell cultures, cells and culture medium from culture I were extracted and analyzed for triterpenes following exposure to the optimal concentrations of MeJA or YE based on transcript induction (Table 1). Over 30 different triterpene glycosides were detected (Table 1), indicating similar diversity of saponins in cell cultures as previously reported in whole plants of M. truncatula (Huhman and Sumner 2002). In MeJA-treated cells, levels of hexose-hederagenin increased strikingly from 2 to 7 days post-elicitation, and hexose-soyasapogenol $\mathrm{E}$ followed similar induction kinetics up to 5 days post-elicitation. Rhamnose-hexosehexose-hederagenin was quantitatively the third most strongly induced saponin. These three saponins were likewise the most strongly induced overall in cells of culture II (Fig. 3), a culture derived from the same initial callus stock as culture I, but older by a further seven passages in liquid culture. However, differences were observed between the responses of the two cultures. For example, at the $48 \mathrm{~h}$ time point, the major triterpenes in culture II were, in order, hexose-soyasapogenol E. hexose-hederagenin, rhamnose-(hexose) - $_{3}$ hederagenin. rhamnose-(hexose) ${ }_{2}$-soyasapogenol $\mathrm{E}$, rhamnose-(hexose) ${ }_{2}$-hederagenin and 3-glucose-28-glucose-medicagenic acid. Of these six compounds, two [rhamnose-(hexose) $3^{-}$ hederagenin and 3-glucose-28-glucose-medicagenic acid] were not among the six most highly induced saponins in culture I. Saponin biosynthesis involves the successive operation of a series of cytochrome P450 monooxygenases and glycosyltransferases (Suzuki et al. 2002). Small differences in the relative expression levels of these enzymes in different cultures could lead to significant changes in the patterns of the complex triterpene saponin mix. 
Table 1 Levels of triterpene saponins in Medicago truncatula cell suspension cultures (culture I) responding to MeJA or YE. Values are relative molecular ion intensities from LC/MS analysis normalized on an equal cell weight basis with the level of hexose hederagenin in nonelicited cells set as 100 . Cultures were treated with $0.5 \mathrm{mM}$ methyl jasmonate (MeJA) or yeast elicitor (YE; $40 \mu \mathrm{g}$ glucose equivalents $\mathrm{ml}^{-1}$ ) and cells or culture medium harvested at the times (days) shown. Hex Hexose, Rha rhamnose, $X$ unidentified triterpene aglycone, Glc glucose, $\mathrm{Ara}$ arabinose, Pen pentose, Glc $A$ glucuronic acid, $X y /$ xylose

\begin{tabular}{|c|c|c|c|c|c|c|c|}
\hline \multirow[t]{3}{*}{ Saponin } & \multicolumn{5}{|l|}{ Cells } & \multicolumn{2}{|c|}{ Medium } \\
\hline & \multicolumn{4}{|l|}{ MeJA } & \multirow{2}{*}{$\begin{array}{l}\text { YE } \\
\text { Day } 7\end{array}$} & \multirow{2}{*}{$\begin{array}{l}\text { MeJA } \\
\text { Day } 7\end{array}$} & \multirow{2}{*}{$\begin{array}{l}\text { YE } \\
\text { Day } 7\end{array}$} \\
\hline & Day 0 & Day 2 & Day 5 & Day 7 & & & \\
\hline Hex-Hederagenin & 100 & 12,774 & 10,8895 & 13,6021 & 27 & 9,477 & 2,234 \\
\hline Hex-Soyaspogenol E & 77 & 20,570 & 62,235 & 62,600 & 44 & 19,656 & 46 \\
\hline Rha-Hex-Hex-Hederagenin & 63 & 981 & 14,457 & 18,491 & 11 & 172 & 38 \\
\hline Hex-X (2) & 13 & 56 & 3,558 & 10,474 & 24 & 876 & 393 \\
\hline Rha-Hex-Hex-Hex-Hederagenin & 73 & 1,839 & 4,708 & 8,775 & 132 & 123 & 32 \\
\hline Rha-Hex-Hex-Soyaspogenol E & 6 & 1,515 & 6,793 & 8,298 & 9 & 379 & 21 \\
\hline Hex-Hex-Bayogenin & 39 & 353 & 6,400 & 8,155 & 25 & 10,291 & 227 \\
\hline 3-Glc-28-Glc-Medicagenic acid & 43 & 474 & 1,885 & 6,690 & 167 & 1,77 & 90 \\
\hline Hex-Hederagenin (2) & 42 & 3,194 & 4,832 & 4,831 & 116 & 1,325 & 872 \\
\hline 3-Glc-Medicagenic acid & 119 & 2,503 & 2,734 & 2,734 & 56 & 46,759 & 4,703 \\
\hline Hex-Hex-Soyaspogenol E & 16 & 1,904 & 2,719 & 2,719 & 28 & 240 & 68 \\
\hline Ara-Hex-Hederagenin & 45 & 595 & 1,477 & 1,476 & 57 & 494 & 90 \\
\hline Pen-Hederagenin & 15 & 593 & 1,057 & 1,057 & 38 & 50 & 119 \\
\hline 3-Glc-Glc-Medicagenic acid & 23 & 783 & 909 & 908 & 16 & 805 & 5,086 \\
\hline Hex-Bayogenin & 5 & 461 & 843 & 843 & 17 & 918 & 164 \\
\hline Hex-Hex-X & 15 & 463 & 415 & 415 & 29 & 688 & 60 \\
\hline 3-Glc-Malonyl-Medicagenic acid & 29 & 146 & 276 & 275 & 40 & 4,077 & 88 \\
\hline Rha-Hex-Hex-Hex-Soyaspogenol E & 12 & 193 & 26 & 261 & 5 & 188 & 37 \\
\hline 3-Glc-Ara-28-Glc-Hederagenin & 34 & 213 & 221 & 220 & 35 & 74 & 59 \\
\hline Hex-Pen-Soyaspogenol E & 8 & 18 & 171 & 171 & 18 & 191 & 49 \\
\hline Rha-Gal-GlcA-Soyaspogenol E & 15 & 129 & 158 & 157 & 8 & 30 & 25 \\
\hline Hex-Hex-Rha-Bayogenin & 6 & 31 & 115 & 115 & 4 & 526 & 44 \\
\hline GlcA-Hederagenin & 18 & 38 & 103 & 102 & 34 & 260 & 268 \\
\hline Hex-Bayogenin (2) & 74 & 51 & 96 & 95 & 27 & 17,105 & 14 \\
\hline Hex-X & 83 & 46 & 28 & 27 & 10 & 1,193 & 405 \\
\hline 3-Glc-28-Glc-Malonyl-Medicagenic acid & 8 & 10 & 26 & 26 & 4 & 106 & 52 \\
\hline Hex-Hex-Hex-Bayogenin & 8 & 4 & 12 & 12 & 4 & 37 & 52 \\
\hline $\begin{array}{l}\text { 3-Glc-Glc-Glc-23-Ara-28-Ara- } \\
\text { Rha-Xyl-Zhanic acid }\end{array}$ & 8 & 10 & 9 & 9 & 4 & 34 & 32 \\
\hline $\begin{array}{l}\text { 3-Glc-Glc-Glc-23-Ara-28-Ara-Rha-Xyl- } \\
\text { Api-Zhanic acid }\end{array}$ & 6 & 5 & 8 & 8 & 5 & 71 & 18 \\
\hline 3-Glc-28-Ara-Rha-Xyl-Medicagenic acid & 5 & 5 & 8 & 8 & 3 & 26 & 21 \\
\hline Soyaspogenol 1 & 6 & 5 & 6 & 6 & 6 & 250 & 20 \\
\hline 3-GlcA-28-Ara-Rha-Xyl-Medicagenic acid & 3 & 5 & 5 & 5 & 2 & 25 & 46 \\
\hline
\end{tabular}

The culture medium from MeJA-elicited cultures of culture I was analyzed, and several saponins were detected (Table 1). Of these, 3-glucose-medicagenic acid attained the highest levels following elicitation. Interestingly, the levels of two bayogenin conjugates, although not induced by MeJA, were higher in the cul- ture medium than in the cells (Table 1). There was no significant increase in any of the saponins in YE-treated cells, and levels remained very low throughout the YE time course (Table 1). Higher levels were found in the culture medium of YE-treated cells, but the quantitatively major compounds in the medium (medicagenic
Fig. 3 Accumulation of triterpene saponins in $M$. truncatula cell suspensions (culture II) exposed to $0.5 \mathrm{mM}$ MeJA. Saponins were identified by LC-MS (Huhman and Sumner 2002). Levels of the six quantitatively most responsive saponins are represented as peak areas in the ion chromatogram (mean and spread of two biological replicates). See Table 1 for further details of the full range of triterpenes identified in Medicago cultures

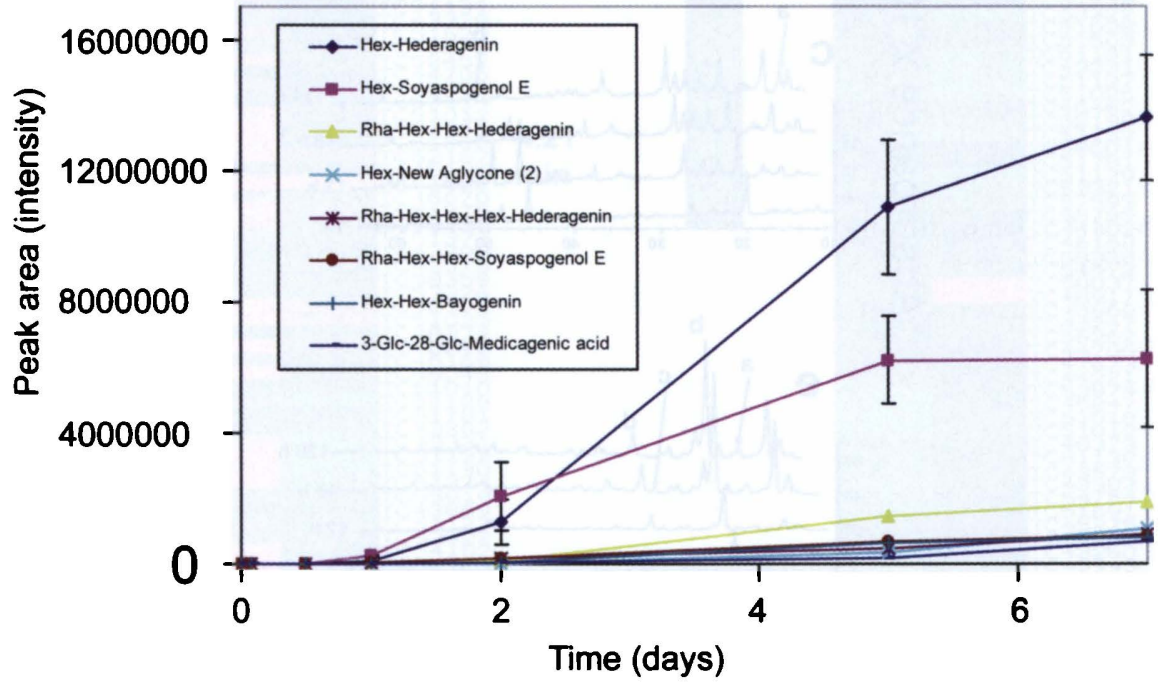


acid conjugates) tended to decrease over time (data not shown).

Most of the studies on saponin production in plant cell cultures have been performed with Panax species, particularly $P$. ginseng (Akalezi et al. 1999; Nosov et al. 2000; Lu et al. 2001). The ginseng saponins, which have demonstrated pharmacological effects in the central nervous, cardiovascular, and endocrine systems, can be induced over 20-fold following exposure to MeJA ( $\mathrm{Lu}$ et al. 2001). However, in contrast to the M. truncatula system, YE has been reported to be an equally effective inducer of saponins in P. ginseng (Lu et al. 2001).

Changes in phenylpropanoid-derived compounds in response to MeJA or YE

Exposure of cells of culture II to YE resulted in gradual increases in the levels of phenolic compounds (derivatives of the phenylpropanoid pathway) in the cells and

Fig. 4a-f HPLC profiles of soluble and cell wall-bound phenolic compounds in $M$. truncatula cell cultures (culture II) following exposure of cells to YE $\left(50 \mu \mathrm{g}\right.$ glucose equivalents $\left.\mathrm{ml}^{-1} ; \mathbf{a}, \mathbf{c}, \mathbf{e}\right)$ or MeJA $(500 \mu \mathrm{M} ; \mathbf{b}, \mathbf{d}, \mathbf{f})$ for the times shown. The panels show traces from soluble cell extracts $(\mathbf{c}, \mathbf{d})$, saponified cell wall material $(\mathbf{e}, \mathbf{f})$. and collected culture medium $(\mathbf{a}, \mathbf{b})$ Identifications of compounds were based on comparison of UV spectra (from diode array detection) and retention times to those of authentic standards. The compounds were: a $a$, 4-hydroxybenzoic acid; $b$, 4-hydroxybenzaldehyde; $c$, medicarpin; b $a$, 4-hydroxybenzoic acid; $b$, vanillin; $c$. medicarpin; $\mathbf{c} a$, protocatechuic acid; $b$, medicarpin conjugate; $\mathbf{d} a$, benzoic acid; $b$, medicarpin conjugate; e, $a, 4$-hydroxybenzoic acid $b$, 4-hydroxybenzaldehyde; c, cis-coumaric acid; $d$, trans-coumaric acid. a,b Absorbance at $270 \mathrm{~nm}$; c-f absorbance at $287 \mathrm{~nm}$
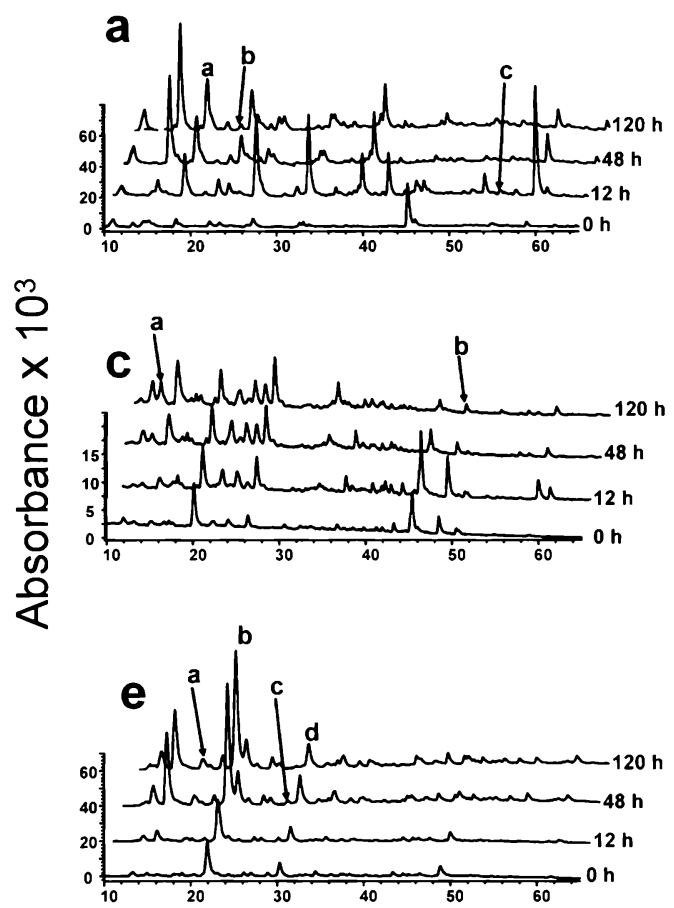

insoluble cell wall fraction (Fig. 4c,e). The isoflavonoid phytoalexin conjugate medicarpin glucoside. a compound previously observed to accumulate in elicited cultures of the related species alfalfa $(M$. satira: Kessmann et al. 1990; Tang and Smith 2001). was identified in the soluble fraction, and p-coumaric acid (both cisand trans-), p-hydroxybenzoic acid and p-hydroxybenzaldehyde were identified in the wall-bound fraction. Essentially identical results were for obtained culture I (data not shown). Changes in the culture medium were more dynamic (Fig. 4a), with a number of compounds reaching maximum levels at $12 \mathrm{~h}$ post-elicitation. and then decreasing; the compounds identified were $p$-hydroxybenzoic acid, $p$-hydroxybenzaldehyde and medicarpin. Perhaps these compounds are further metabolized by oxidases present in the culture medium. as has been suggested for similar phenolic compounds in chickpea cell cultures (Barz 1977). No compounds accumulated in control cells or culture medium after treatment of cultures with water in place of $\mathrm{YE}$ (data not shown).

Except for an approximate doubling of an unidentified compound eluting with a retention time of $20 \mathrm{~min}$ in the soluble fraction (Fig. 4d), exposure of cells to $500 \mu \mathrm{M} \mathrm{MeJA}$ resulted in little effect on levels of phenylpropanoid compounds (note the reduced scales in Fig. 4b,f).

Elicitor-mediated accumulation of phenylpropanoid compounds in plant cell cultures has been studied in greatest detail in parsley, chickpea, soybean and alfalfa cells (Kombrink and Hahlbrock, 1986; Barz and Mackenbrock 1994; Dixon 1999). Parsley cell cultures and protoplasts derived from them respond differently
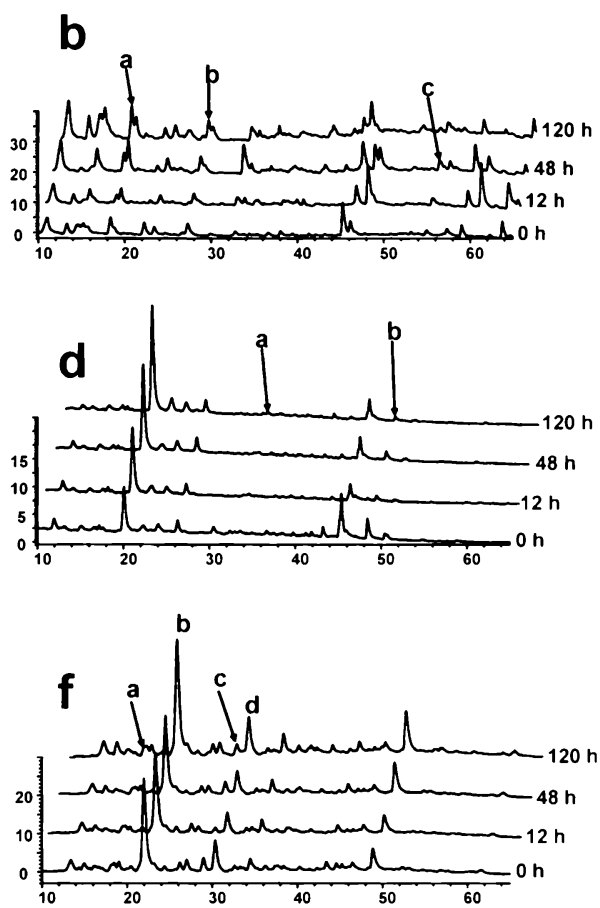

\section{Retention time ( $\mathrm{min})$}


to UV light and fungal elicitor (Dangl et al. 1987), with elicitor inducing furanocoumarin phytoalexins and UV light inducing flavonoid glycosides. In legumes such as alfalfa, soybean and chickpea, the major response to yeast or fungal elicitors is accumulation of isoflavonoid phytoalexins and related compounds (Barz and Mackenbrock 1994; Dixon 1999). In the $M$. trincatula cultures, the fold-induction of soluble isoflavonoids (medicarpin and its conjugate) in response to YE was significantly lower than previously reported in alfalfa cultures exposed to Colletotrichum elicitor (Dalkin et al. 1990), in spite of the high fold-induction of PAL and CHS transcripts. In cells of Pueraria lobata exposed to yeast elicitor, isoflavonoids can oligomerize and become insolubilized into cell walls (Hakamatsuka et al. 1992; Park et al. 1995).
DNA microarray analysis of MeJA- and YE-induced natural product pathway gene transcripts

Glass slides printed with the Medicago Genome Oligo Set Version 1.0 (Qiagen) were used to analyze gene expression in elicited and control cells of culture II. Poly $(\mathrm{A})^{+}$mRNA was extracted from triplicate biological samples of 2-h- and 24-h-elicited cells, and read against mRNA from zero-time cells of the same batch.

The array data were analyzed for changes in transcripts encoding all known enzymes of the phenylpropanoid, flavonoid, isoflavonoid and triterpene pathways (Fig. 5). In addition to providing a more global analysis of the pathways predicted to be induced on the basis of analysis of just three key pathway genes in Figs. 1 and 2, this also enabled evaluation of changes in individual gene family
Fig. 5a,b DNA microarray analysis of phenylpropanoid and triterpene pathway gene induction in $M$. truncatula cell suspensions (culture II) responding to $\mathrm{YE}(50 \mu \mathrm{g}$ glucose equivalents $\mathrm{ml}$, or MeJA $(0.5 \mathrm{mM})$. The analysis targets gene transcripts corresponding to individual genes (TCs) from multigene families. Panels show colorcoded array data for the responses at $2 \mathrm{~h}$ and $24 \mathrm{~h}$ post-elicitation to $\mathrm{YE}$ (a) and MeJA (b)

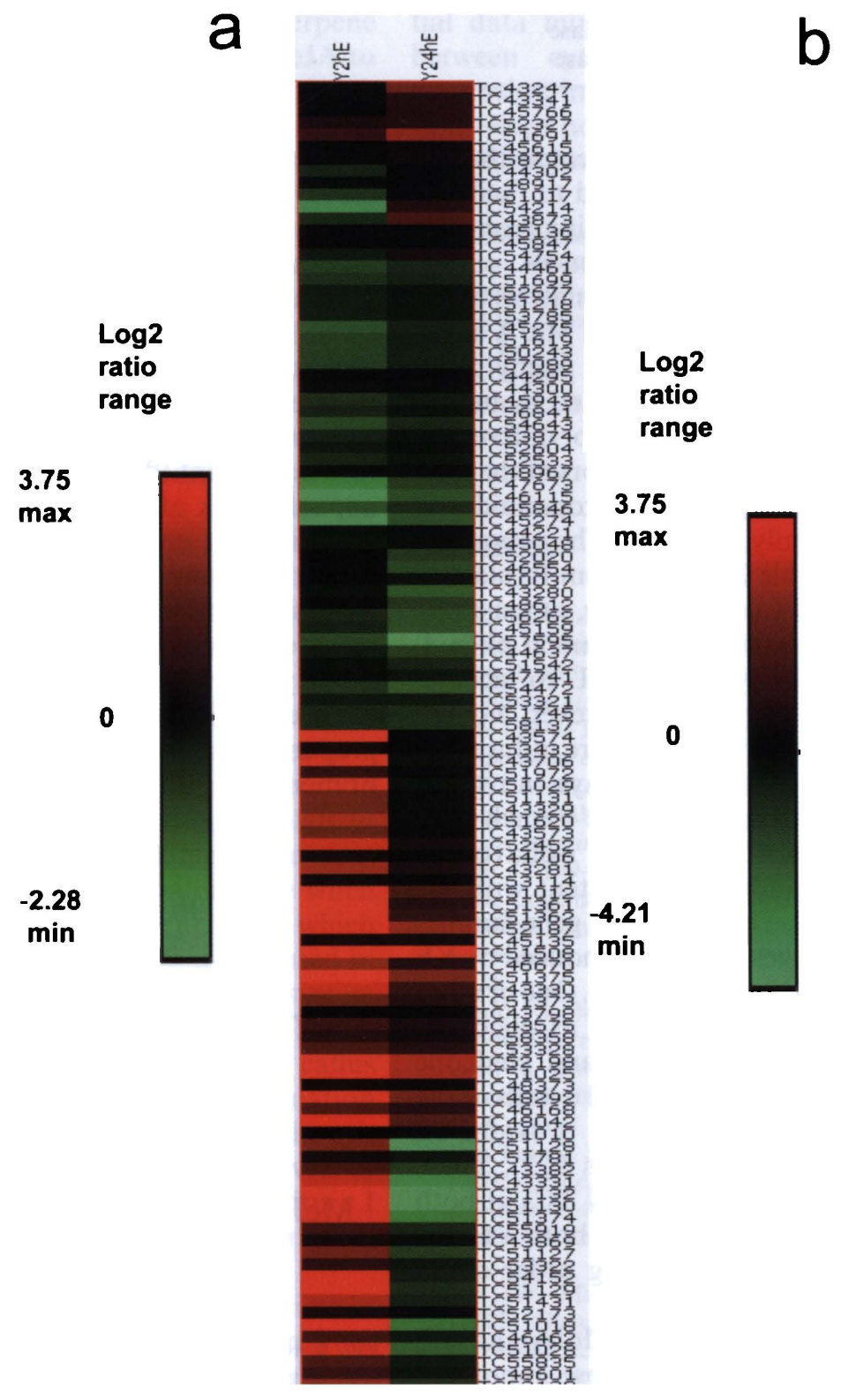


Table 2 Summary of microarray analysis of the response of $M$. truncatula phenylpropanoid and triterpene pathway genes to $Y E$ and MeJA in culture II. For each enzyme, the first column indicates the number of different gene family members (TCs) present on the microarray. The other columns indicate the number of gene family members either induced $(\uparrow)$ or repressed $(\downarrow)$ more than 2 -fold in response to YE (at $2 \mathrm{~h}$ post-elicitation) or MeJA (at $24 \mathrm{~h}$ post-elicitation). For details of the responses of all individual TCs at both time points, see Supplementary Electronic Material

\begin{tabular}{llllll}
\hline Enzyme & \# of TCs & \#YE $\uparrow$ & \#YE $\downarrow$ \#MeJA $\uparrow$ \#MeJA $\downarrow$ \\
\hline L-Phenylalanine ammonia-lyase (PAL) & 9 & 6 & 0 & 1 & 0 \\
Cinnamate 4-hydroxylase (C4H) & 2 & 2 & 0 & 1 & 0 \\
4-Coumarate:Coenzyme A ligase (4CL) & 10 & 3 & 1 & 4 & 0 \\
Caffeic acid 3- $O$-methyltransferase (COMT) & 4 & 1 & 0 & 1 & 0 \\
Caffeoyl Coenzyme A 3- $O$-methyltransferase (CCOMT) & 5 & 1 & 0 & 1 & 0 \\
Ferulate 5-hydroxylase (F5H) & 1 & 0 & 0 & 0 & 0 \\
Cinnamoyl coenzyme A reductase (CCR) & 4 & 0 & 0 & 1 & 1 \\
Cinnamyl alcohol dehydrogenase (CAD) & 4 & 2 & 0 & 1 & 0 \\
Laccase & 11 & 3 & 1 & 1 & 1 \\
Chalcone synthase (CHS) & 18 & 11 & 0 & 0 & 2 \\
Chalcone reductase (CHR) & 6 & 3 & 2 & 1 & 3 \\
Chalcone isomerase CHI & 3 & 1 & 0 & 0 & 0 \\
Flavanone 3- $\beta$-hydroxylase (F3 $\beta$ H) & 1 & 0 & 0 & 0 & 0 \\
Flavanone 3'-hydroxylase (F3'H) & 3 & 0 & 0 & 0 & 0 \\
Flavonoid 3',5'-hydroxylase & 3 & 0 & 0 & 0 & 0 \\
Dihydroflavonol reductase (DFR) & 3 & 0 & 0 & 0 & 1 \\
Anthocyanidin synthase (ANS) & 5 & 0 & 0 & 2 & 0 \\
Isoflavone synthase (IFS) & 2 & 1 & 0 & 0 & 2 \\
Isoflavone $O$-methyltransferase (IOMT) & 4 & 1 & 0 & 1 & 1 \\
Isoflavone reductase (IFR) & 9 & 4 & 0 & 4 & 2 \\
Squalene synthase & 1 & 0 & 1 & 1 & 0 \\
Squalene epoxidase & 4 & 0 & 1 & 1 & 0 \\
$\beta$-Amyrin synthase & 2 & 0 & 0 & 2 & 0 \\
\hline
\end{tabular}

members in response to MeJA and YE because the oligonucleotides on the arrays were optimized to facilitate discrimination between transcripts originating from different ESTs belonging to different TC sequences.

Figure 5 provides a color-coded cluster analysis of the patterns of response of culture II to YE and MeJA at the level of individual TCs for genes within the phenylpropanoid and triterpene pathways, as determined by microarray analysis. This provides clear evidence for differential gene expression in response to the two elicitors at the level of all currently known Medicago phenylpropanoid and triterpene pathway gene family members. The overall results are summarized in Table 2. Apart from ferulate 5hydroxylase and cinnamoyl $\mathrm{CoA}$ reductase, at least one member of every gene family within the general phenylpropanoid/monolignol pathway (from PAL to laccase) was induced at least 2-fold by YE. However, not all members within a particular gene family were induced by YE. In the flavonoid/isoflavonoid pathways, no genes encoding members of the flavonoid-specific branch were induced more than 2-fold, but several isoflavonoid branch-specific genes were induced, consistent with the metabolite analysis in Fig. 4. The annotated gene families in which the largest percentage of TCs was induced by YE were PAL ( 6 out of 9 ) and CHS (11 out of 18). One or more family members for the genes annotated as encoding 4-coumarate: CoA ligase (4CL), laccase and chalcone reductase (CHR) were repressed by YE. Full details of the changes in all of the individual TCs are provided as Electronic Supplementary Material (Tables 1, 2). These document the numerical fold-changes in all TCs at both $2 \mathrm{~h}$ and $24 \mathrm{~h}$ post-elicitation in response to both $\mathrm{YE}$ and MeJA, with the genes listed in descending order of induced expression level.

A comparison of the global effects of MeJA and YE indicated that, for some genes, such as those annotated as encoding PAL and CHS, most members of the gene family were induced by YE, but few or no members were induced by MeJA. The triterpene pathway genes were induced by MeJA but not by YE. In the case of genes annotated as encoding $4 \mathrm{CL}$ and anthocyanidin synthase (ANS), more TCs were induced in response to MeJA than in response to YE. Such information can be helpful in directing functional studies for gene annotation. For example, ANS is a member of a family of 2-oxoglutarate-dependent dioxygenases (Saito et al. 1999). The apparent lack of induction of anthocyanidins, or of TCs encoding the enzymes preceding ANS in the anthocyanidin pathway, in the cell cultures treated with MeJA suggests that the Medicago ANS TCs that are induced by MeJA might represent related dioxygenases with activity against non-flavonoid substrates.

Selected transcripts were amplified from total RNA preparations by RT-PCR using gene (TC)-specific primers (Fig. 6). This analysis confirmed the differential

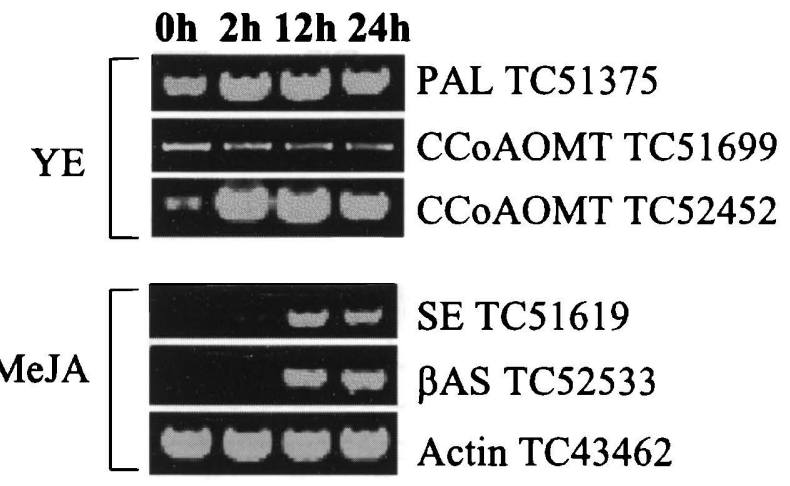

Fig. 6 RT-PCR analysis of gene expression in response to YE $\left(50 \mu \mathrm{g}\right.$ glucose equivalents $\left.\mathrm{ml}^{-1}\right)$ or MeJA $(0.5 \mathrm{mM})$ in culture II 
patterns of gene expression observed by microarray analysis. such as the up-regulation of CCoAOMT TC52452 and down-regulation of TC51699 by YE. The RT PCR analysis also confirmed induction of CHS and isoflavone synthase in response to YE (data not shown).

Summary and conclusions: elicited cell cultures as model systems for functional genomics

The metabolic response of suspension-cultured cells to biotic and abiotic elicitors has been studied in greatest detail in parsley, in which formation of either furanocoumarins or flavonoids is associated not only with changes in the genetic machinery underlying these pathways, but also with changes in related primary metabolism (Batz et al. 1998; Logemann et al. 2000). However, unlike $M$. truncatula, parsley does not have strong genomics resources. We previously developed an elicitor-inducible cell suspension system for triterpene pathway gene discovery in M. truncatula, using MeJA to reprogram secondary metabolism into the saponin pathway as assessed by measurement of $\beta$ AS induction (Suzuki et al. 2002). We have now extended the studies on MeJA induction to include detailed profiling of the saponin glycosides produced in the cultures, along with preliminary studies on the classes of phenylpropanoid compounds induced by YE. The system was optimized in relation to elicitor concentration, and the times of transcript appearance and accumulation of specific pathway end products in the cultures were defined. Further studies are in progress to more fully catalog the metabolic changes, for both primary (Broeckling et al. 2004) and secondary metabolites, in order to realize the full potential of the M. truncatula system for gene discovery.

The specific growth stage of a cell suspension culture can have a large effect on its elicitor responsiveness (Kombrink and Hahlbrock 1985). Furthermore, small changes in growth rate between different passages of the same culture, and accumulating epigenetic changes as a function of time in culture, mean that expression data from one culture batch will not necessarily extrapolate to another batch. even if that batch is simply the next passage of the same culture. This is a major issue when using cell cultures for genomics experiments from which large datasets are made publicly available, to be used in conjunction with data from the same biological system generated in different laboratories. In the present study, two different cultures derived from the same root callus were compared in relation to triterpene accumulation patterns in response to MeJA (Table 1, Fig. 3). Although the responses at first sight appeared similar, the levels of the six major triterpene saponins were higher in culture I than in culture II at $48 \mathrm{~h}$ post-elicitation. Furthermore, qualitative differences were also observed.

Although metabolic variation as a function of time in culture has been seen as a problem with plant cell culture studies, this natural variation can be harnessed to pro- vide a powerful tool for gene discovery, particularly since the advent of global methods for profiling transcriptome and metabolome. At the same time, however, large-scale integrated genomics approaches relying on correlations between transcript, protein and metabolite datasets require the use of carefully controlled biological material without the sort of inter-passage variation seen with most cell cultures. For this reason, we have performed a very large-scale elicitation experiment on a further passage of the cultures described in the present work, utilizing three elicitors (YE, MeJA and UV light), 21 time points (elicited and control), and triplicate biological samples per treatment, to provide sufficient material for parallel analysis of transcriptome (using the $16 \mathrm{~K}$ oligonucleotide chip), proteome and metabolome. Work is in progress to generate a database ("DOME" or database of "omes"), to house this information as a resource for understanding the molecular genetic basis of induced secondary metabolism in a model legume. Initial data mining will concentrate on the relationships between cytochrome P450 and glycosyltransferase expression in relation to triterpene glycoside accumulation, since none of the downstream genes in the Medicago triterpene pathway has yet been identified.

Acknowledgements We thank Dr. David Galbraith, University of Arizona, for printing the DNA microarrays, and Drs. Matthew Templeton (HortResearch, Auckland, New Zealand) and Ajith Anand for critical reading of the manuscript. This work was supported by the National Science Foundation Plant Genome Research Award \#DBI-0109732, and the Samuel Roberts Noble Foundation. H. Suzuki and M.S.S. Reddy contributed equally to this work.

\section{References}

Akalezi CO, Liu S, Li QS, Yu JT, Zhong JJ (1999) Combined effects of initial sucrose concentration and inoculum size on cell growth and ginseng saponin production by suspension cultures of Panax ginseng. Process Biochem 34:639-642

Barz W (1977) Degradation of polyphenols in plants and plant cell suspension cultures. Physiol Veg 15:261--277

Barz. W, Mackenbrock U (1994) Constitutive and elicitation induced metabolism of isoflavones and pterocarpans in chickpea (Cicer arietinum) cell suspension cultures. Plant Cell Tissue Org Cult 38:199 211

Batz O, Logemann E, Reinold S, Hahlbrock K (1998) Extensive reprogramming of primary and secondary metabolism by fungal elicitor or infection in parsley cells. Biol Chem 379:11271135

Behboudi S, Morein B, VillacresEriksson MC (1999) Quillaja saponin formulations that stimulate proinflammatory cytokines elicit a potent acquired cell-mediated immunity. Scand J Immunol 50:371-377

Bestel-Corre G, Dumas-Gaudot E, Poinsot V, Dieu M, Dicrick JF, van Tuinen D, Remacle J, Gianinazzi-Pearson V, Gianinazzi S. (2002) Proteome analysis and identification of symbiosis-related proteins from Medicago truncatula Gaertn. by two-dimensional electrophoresis and mass spectrometry. Electrophoresis 23:12237

Blount JW, Masoud S, Sumner LW, Huhman DV, Dixon RA (2002) Over-expression of cinnamate 4-hydroxylase leads to increased accumulation of acetosyringone in elicited cell-suspension cultures. Planta 214:902-910 
Broeckling CD, Huhman DV, Farag M, Smith JT, May GD, Mendes P, Dixon RA, Sumner LW (2004) Metabolic profiling of Medicago truncatula cell cultures reveals effects of biotic and abiotic elicitors on metabolism. J Exp Bot (in press)

Cook DR (1999) Medicago truncatula-a model in the making! Curr Opin Plant Biol 2:301-304

Dalkin K, Edwards R, Edington B, Dixon RA (1990) Stress responses in alfalfa (Medicago sativa L.) I. Elicitor-induction of phenylpropanoid biosynthesis and hydrolytic enzymes in cell suspension cultures. Plant Physiol 92:440 446

Dangl JL, Hauffe KD, Lipphardt S, Hahlbrock K, Scheel D (1987) Parsley protoplasts retain differential responsiveness to u.v. light and fungal elicitor. EMBO J 6:2551-2556

d'Erfurth I, Cosson V, Eschstruth A, Lucas H, Kondorosi A, Ratet P (2003) Efficient transposition of the Tnt lobacco retrotransposon in the model legume Medicago truncatula. Plant J 34:95-106

Dixon RA (1999) Isoflavonoids: biochemistry, molecular biology and biological functions. In: Sankawa U (ed) Comprehensive natural products chemistry. Elsevier, Amsterdam, pp 773-823

Dixon RA, Fuller KW (1978) Effects of growth substances on noninduced and Botrytis cinerea culture filtrate-induced phaseollin production in Phaseolus vulgaris cell suspension cultures. Physiol Plant Pathol 12:279 288

Dixon RA, Sumner LW (2003) Legume natural products. Understanding and manipulating complex pathways for human and animal health. Plant Physiol 131:878--885

Dixon RA, Dey PM, Murphy DL, Whitehead IM (1981) Dose responses for Colletotrichum lindemuthianum elicitor-mediated enzyme induction in French bean cell suspension cultures. Planta 151:272-280

Dixon RA, Harrison MJ, Paiva NL (1995) The isoflavonoid phytoalexin pathway: from enzymes to genes to transcription factors. Physiol Plant 93:385-392

Goss V, Tusher VG, Tibshirani R, Chu G (2001) Significance analysis of microarray applied to the ionizing radiation response. Proc Natl Acad Sci USA 98:5116-5121

Hakamatsuka T, Shinkai K, Noguchi H, Ebizuka Y, Sankawa U (1992) Isoflavone dimers from yeast extract-treated cell suspension cultures of Pueraria lobata. Z Naturforsch Teil C 47:177-182

Haridas V, Higuchi M, Jayatilake GS, Bailey D, Mujoo K, Blake ME, Arntzen CJ, Gutterman JU (2001) Avicins: triterpenoid saponins from Acacia victoriae (Bentham) induce apoptosis by mitochondrial perturbation. Proc Natl Acad Sci USA 98:58215826

Hildmann T, Ebneth M, Peña-Cortés H, Sánchez-Serrano JJ, Willmitzer L, Prat S (1992) General roles of abscisic and jasmonic acids in gene activation as a result of mechanical wounding. Plant Cell 4:1157-1170

Howles PA, Sewalt VJH, Paiva NL, Elkind NL, Bate Y, Lamb CJ. Dixon RA (1996) Overexpression of L-phenylalanine ammonialyase in transgenic tobacco plants reveals control points for flux into phenylpropanoid biosynthesis. Plant Physiol 112:16171624

Huhman DV, Sumner LW (2002) Metabolic profiling of saponin glycosides in Medicago sativa and Medicago truncatula using HPLC coupled to an electrospray ion-trap mass spectrometer. Phytochemistry 59:347-360

Kessmann H, Choudhary AD, Dixon RA (1990) Stress responses in alfalfa (Medicago sativa L.) III. Induction of medicarpin and cytochrome P450 enzyme activities in elicitor-treated cell suspension cultures and protoplasts. Plant Cell Rep 9:38-41

Klessig DF, Malamy J (1994) The salicylic acid signal in plants. Plant Mol Biol 26:1439-1458

Kombrink E, Hahlbrock K (1985) Dependence of the level of phytoalexin and enzyme induction by fungal elicitor on the growth stage of Petroselinum (rispum cell cultures. Plant Cell Rep 4:277-280

Kombrink E, Hahlbrock K (1986) Responses of cultured parsley cells to elicitors from phytopathogenic fungi. Timing and dose dependency of elicitor-induced reactions. Plant Physiol 81:216 221
Lee SJ, Ko WG, Kim JH. Sung JH. Lee SJ. Moon CK. Lee BH (2000) Induction of apoptosis by a novel intestinal metabolite of ginseng saponin via cytochrome (-mediated activation of caspase-3 protease. Biochem Pharmacol 60:677 685

Logemann E. Tavernaro A. Schulz. WG. Somssich IE. Hahlbrock K (2000) UV light selectively coinduces supply pathways from primary metabolism and flavonoid secondary product formation in parsley. Proc Natl Acad Sci USA 97:1903 1907

Lu MB. Wong HL. Teng WL (2001) Effects of elicitation on the production of saponin in cell culture of Pancox ginse'ng. Plant Cell Rep 20:674 677

Mathesius U. Keijzers G. Natera SHA. Winman JJ. Djordjevic MA. Rolfe BG (2001) Establishment of a root proteome reference map for the model legume. Medicuge truncatula using the expressed sequence tag database for peptide mass fingerprinting. Proteomics 1:1424 1440)

May GD, Dixon RA (2004) Quick guide Medicago truncatula. Curr Biol 14:R180 181

Mueller MJ. Brodschelm W. Spannagl E. Zenk MH (1993) Signaling in the elicitation process is mediated through the octadecanoid pathway leading to jasmonic acid. Proc Natl Acad Sci USA 90:7490 7494

Nosov AV. Globa EB. Kulichenko IE. Reshetnyak (OV. Sobolkova GI (2000) Effect of 5-iracytidine, at tool for epigenetic control. on saponin synthesis in cell cultures of Dioscoreda deltoidea and Panax quinquefolium. Russ J Plant Physiol 47:407 416

Oh SR, Kinjo J. Shii T, lkeda T. Nohara T. Ahn KS. Kim JH. Lee HK (2000) Effects of triterpenoids from Pucraria lohata on immunohemolysis: beta-1)-glucuronic acid plays an active role in anticomplementary activity in vitro. Planta Med 66:506510

Oldroyd GE. Geurts R (2001) Medicago trumcatula. going where no plant has gone before. Trends Plant Sci 6:552.554

Oleszek W. Junkuszew M. Stochmal A (1999) Determination and toxicity of saponins from Amaranthus crucutus seeds. J Agric Food Chem 47:3685 3687

Osbourn AE (2003) Molecules of interest. Saponins in cereals. Phytochemistry 62:1--4

Park HH. Hakamatsuka T, Sankawa U. Ebizuka Y (1995) Rapid metabolism of isoflavonoids in elicitor-treated cell suspension cultures of Pueraria lohata. Phytochemistry 38:373 380

Saito K. Kobayashi M. Gong Z. Tanaka Y. Yamazaki M (1999) Direct evidence for anthocyanidin synthase as a 2-oxoglutaratedependent oxygenase: molecular cloning and functional expression of cDNA from a red forma of Perilla frutescens. Plant J 17:181-189

Sambrook J, Fritsch EF. Maniatis T (1989) Molecular cloning. A laboratory manual. Cold Spring Harbor Laboratory Press. New York

Schumacher H-M. Gundlach H. Fiedler F. Zenk MH (1987) Elicitation of benzophenanthridine alkaloid synthesis in Eschischoltzia cell cultures. Plant Cell Rep 6:410 413

Shimada N. Akashi T. Aoki T. Ayabe $S(200)(0)$ Induction of isoflavonoid pathway in the model legume Lotus juponicus: molecular characterization of enzymes involved in phytoalexin biosynthesis. Plant Sci 160:37 47

Shirasu K. Nakajima H. Rajasekhar VK. Dixon RA. Lamb CJ (1997) Salicylic acid potentiates an agonist-dependent gain control that amplifies pathogen signals in the activation of defense mechanisms. Plant Cell 9:261 270

Small E (1996) Adaptations to herbivory in alliallal (.Medicugo sottiv' $(t)$. Can J Bot 74:807-822

Steele CL. Gijzen M. Qutob D. Dixon RA (1999) Molecular characterization of the enzyme catalyzing the aryl migration reaction of isoflavonoid biosynthesis in soybean. Arch Biochem Biophys 367:147-150

Sumner LW. Mendes P. Dixon RA (20)(3) Plant metabolomics: large-scale phytochemistry in the functional genomics era. Phytochemistry 62:817 836

Suzuki H. Achnine L. Xu R. Matsuda SPT. Dixon RA (2)()2) A genomics approach to the early stages of triterpene saponin biosynthesis in Medicago truncutula. Plant J 32:1033 1048 
Tang M, Smith C.J (2001) Elicitor induced defence responses in Medicago sativa. New Phytol 149:401 418

Tava A, Odoardi M (1996) Saponins from Medicago spp: chemical characterization and hiological activity against insects. In: Waller GR, Yamasaki T (eds) Saponins used in food and agriculture. Plenum, New York, pp 97-109
Watson BS, Asirvatham VS, Wang L, Sumner LW (2003) Mapping the proteome of barrel medic (Medicago truncatula). Plant Physiol 131:1104-1123

Xu Y (2001) Perspectives on the 21st century development of functional foods: bridging Chinese medicated diet and functional foods. Int J Food Sci Technol 36:229-242 